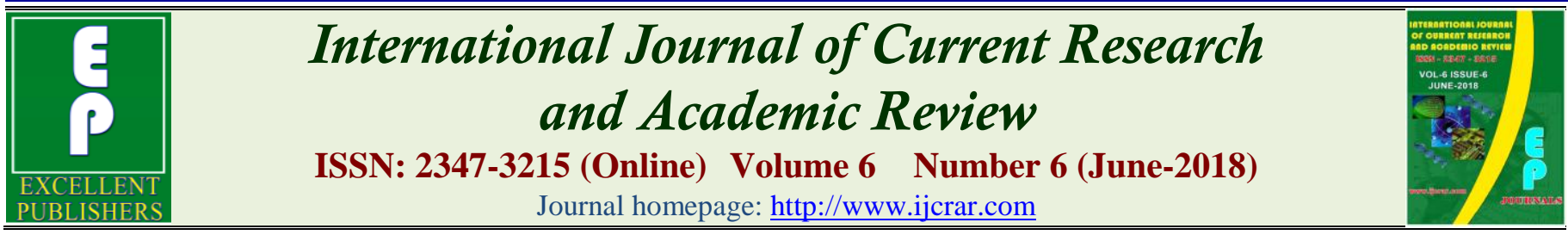

doi: https://doi.org/10.20546/ijcrar.2018.606.011

\title{
Role of Ultrasound in Cataract Surgery -A Prospective Clinical Study
}

\author{
Nadya Abid Hadi*
}

M.B.Ch.B, CABS-Ophth., Ophthalmologist, Department of ophthalmology, Gazi Al-Harere Teaching Hospital for Surgical specialization, Iraq

*Corresponding author

\section{Abstract}

Ultrasound examination prior to cataract surgeries can be very useful to get significant information about the ocular abnormalities and changes found among patients intended to have cataract surgeries. This prospective study aimed to assess and evaluate the role of ultrasound examination in detection of abnormal findings among 168 Iraqi patients before cataract surgery, all patients were examined with ultrasound prior to surgery. Postoperatively, the patients were followed up in scheduled visits for three months. The mean age of the studied group was $58.2 \pm$ 14.7 ranged between 38 and 81 years, males were $44.6 \%$ and females were $55.4 \%$. Obese patients were $38.7 \%$, hypertensive $22.6 \%$, diabetic $14.3 \%$, surgical history in $16.1 \%$, smokers were $31.5 \%$, and only $1.8 \%$ were alcohol consumer. Abnormal ultrasound findings found in 21 patients $(12.5 \%)$. Retinal detachment was the more frequent abnormal ultrasound finding account fo $(6.5 \%)$, followed by vitreous hemorrhage $(4.2 \%)$, other lesions were less frequent account for 1.2 , to $1.8 \%$. Abnormal ultrasound findings were significantly associated with younger age below 50 years (Odds ratio $=3, \mathrm{P}=0.026$ ) and diabetes mellitus (Odds ratio $=3.82$ $\mathrm{P}=0.019$ ). No statistically significant association had been found with other characteristics of patients. In conclusion, the detected abnormal findings on ocular ultrasonography before cataract surgery reflected that ultrasonography examination before cataract surgery can play a significant role in diagnosis and detection of hidden lesions to help in planning for surgeries and to get more precise prognostic information.
\end{abstract}

\section{Article Info}

Accepted: 30 May 2018

Available Online: 20 June 2018

\section{Keywords}

Cataract, Cataract surgery, Ocular ultrasonography

\section{Introduction}

Cataract is the leading cause of blindness and cataract extraction is the most common intraocular surgery performed worldwide. Cataract is an extremely common condition, especially in the elderly, caused by the partial or total opacification of the natural lens of the eyes (Grimfors, Lundstrom, Hoijer, \& Kugelberg, 2017). It is a disease of slow and progressive evolution, being currently the main cause of vision loss in the world. About 160 million people worldwide suffer from cataract to a certain degree. Among the population over 65 years of age, almost half of individuals have this disease. Despite being a common cause of blindness, fortunately cataracts are curable and can be corrected by surgery (Abraham AG, Condon NG, 2006). Even patients with advanced stages can see again. Naturally the lens is transparent, biconvex and gelatinous located behind the iris and the pupil. Since it is flexible, the angle of curvature through the contraction of the eye muscles can be changed, which allows focusing on objects from far or near with equal effectiveness. The lens is composed, 
basically, by water and proteins. The crystalline proteins have their own characteristics and are responsible for clarity and transparency. With the aging of the eyes, the structure of these proteins is altered, which causes a gradual loss of the transparency of the lens. Cataract occurs when the lens of the eye loses its natural transparency and becomes progressively opaque, blurred or unnerved vision. In advanced cases, the patient loses vision completely (Candia, 2004; Duker, Myron Yanoff, 2008). The main symptom is a gradual clouding, sometimes associated with frontal-light blinding and image duplication. The lens is composed, basically, by water and proteins. The crystalline proteins have their own characteristics and are responsible for clarity and transparency. With the aging of the eyes, the structure of these proteins is altered, which causes a gradual loss of the transparency of the lens (Andley, 2007). Senile cataract in elderly people is the most common type of cataract.

In addition to senile cataract, there are other causes for loss of lens transparency, including congenital cataract, traumatic cataract, cataract by radiation, and cataract secondary to medications if used continuously for several years, such as glucocorticoids, statins and drugs used in the treatment of high cholesterol. Cataract is multifactorial and there are many risk factors contributed in its appearance; older age particularly above 70 years of life, smoking, excessive alcohol consumption, obesity, diabetes mellitus, sedentary life style, hypertension, infection with HIV virus and family history are important risk factors of cataract (Abraham AG, Condon NG, 2006; Joshi, 2013; Thanigasalam, Reddy, \& Zaki, 2015) However, cataract is a slow, gradual and painless process, in the earlier stages it can be unobservable and been unnoticed, in most cataract cases it is bilateral affecting both eyes, but usually it is asymmetrical. Generally, one eye affected by cataract in later stage than the other one. In vast majority of the cases the first complaints of the patients tend to be difficult seeing in poorly lighted places, driving at night and difficulty in reading small letters and signs. Myopia could be aggravated by cataract and is also a common symptom. Furthermore, another sign of cataract is the need to change the degree of glasses. When the opacification of the lens progressed, there is an increase in the cloudy vision with less noticeable contrast. Some patients might be uncomforting strong light and complaints about color vision or having double vision (Abraham AG, Condon NG, 2006; Candia, 2004; Corrêa, Goldhardt, Marcon, \& Marcon, 2002; Duker, Myron Yanoff, 2008; Joshi, 2013).
The opacified grey lens could be seen through the pupil in more advanced stages, however, it need many years to reach this status (Figure 1). Surgery is the only effective treatment of cataract, while glasses and magnifying glasses could alleviate the phases of onset of symptoms but not solve the problem. When the lens opacification is large enough that interfere with common activities of the patients, the surgery is indicted. Among children, the decision about surgery is much different, where surgery performed when the diagnosis of cataract is made because cataract could interfere with development of the eyes of the affected babies. Cataract surgery is simple involving the removal of opacified lens and replaced with an artificial one (Thanigasalam et al., 2015).

Phacoemulsification surgery is performed by a small incision, less than $3 \mathrm{~mm}$ in the cornea. using ultrasound waves which fragment the broken lens into several pieces then, after the defective lens is all removed, a new intraocular lens (IOL) is inserted.

The artificial lens can be multifocal, which in addition to curing the cataract also allows the patient to no longer need glasses for far or near. After the cataract surgery, the vision progressively returns, but generally, in the first days, the visual acuity is already very good. Generally, for safety reasons, the ophthalmologist operates one eye at a time. The interval between the two surgeries depends on the recovery of the first one. As the complete healing of the surgery takes 4 to 8 weeks, this is usually the interval between the two operations. (Ej, Gk, \& Rl, 2018)

\section{Sonographic examination and cataract surgery}

Ultrasound was first used in ophthalmology in 1956 by the American ophthalmologists, Mundt and Hughes. They used A-scan mode to evaluate an intraocular tumor. B-scan was introduced in ophthalmic practice by Baum and Greenwood in 1958. Both A-scan and B-scan techniques are important for the diagnosis of posterior segment lesion. B (Brightness) mode is useful for a better demonstration of the shape and topographic relationship of lesions in the posterior segment. B-scan provides cross sectional display of diseased tissues and is valuable in detecting unsuspected posterior segment diseases (Qureshi \& Laghari, 2010; Zafar, Mirza, \& Adul Qadeer, 2008). Over the last 30 years ultrasonography has greatly advanced and this has enabled us to study posterior segment of the eye in the presence of opaque media. Its most common use is in a contact mode for evaluation of the posterior segment in eyes with media opacification (Qureshi \& Laghari, 2010). 
With the advancement of cataract surgery and the increasing requirement of patients for better visual results and the ophthalmologist for greater predictability of these, it is of fundamental importance to determine the existence of other ocular changes and, where possible, their visual effects in patients with cataract. For this, tests are currently used to evaluate the visual potential of these patients, among them the potential acuity meter (PAM) and interferometry are the most used. However, these tests do not present good reliability in patients with mature cataract and very low visual acuity. In these cases the ultrasound, although it does not determine the potential visual acuity, is the most used to diagnose eventual anatomical changes in the posterior segment that may compromise the postoperative visual result (Chavda, Shah, \& Sharma, 2017; Thanigasalam et al., 2015). Ultrasonography is an important tool for evaluating the posterior segment in eyes with opaque media and provides a method of assessing the structural changes in the posterior segment of the eye in such patients (Chavda et al., 2017; Thanigasalam et al., 2015). Hence the current study tried to assess the role of ultrasound in cataract surgeries.

\section{Patients and Methods}

This was a prospective study conducted at the Department of Ophthalmology in Gazi Al Harere for surgical specialization Hospital during a period of one year (2015-2016). The study included 168 consecutive cataract adult patients (168 eyes). The inclusion criteria were adult patients aged 18 years or more of both gender enrolled in this study prior to cataract surgery. Patients was excluded from the study if he/she had one or more of the following: already found posterior segment lesions, previous history of ocular surgery and previous history of perforating trauma. Non-consenting patients or refused to participate in the study were also excluded from the study. Full history and complete clinical examination were made in all patients. Before cataract surgery all patients were examined with ocular ultrasonography as a preoperative assessment. Ultrasonography examination was made using ultrasound $\mathrm{A} / \mathrm{B}$ scan system and the ultrasound examination findings were reported. Fundoscopic examination was also performed when it is possible and not impaired by opacity Additionally, all patients underwent contralateral eye examination. Verbal and written signed consent were obtained from all patients.

Routine preoperative investigations were performed and all patients prepared for operation. All patients were put on topical antibiotic drops 1 day prior to surgery. Patient operated on by the same surgeon (researcher) under local anesthesia using Peribulbar block with $5 \mathrm{ml}$ of $2 \%$ xylocaine and $5 \mathrm{ml}$ of $0.5 \%$ bupivacaine with 150 units $/ \mathrm{ml}$ of hyaluronidase. Povidine-iodine 5\% was instilled into the conjunctival sac. Intra-ocular artificial lens inserted. Post-operatively, patients were put on topical antibiotics. Follow-up through scheduled visits for three months on day one, 7, 15 and 30 postoperative days for the first month and at each two weeks in the next two months looking for improvement in vision and quality of life of the patients and to assess intraocular pressure, presence of intraocular inflammation, decentration/tilt of intra ocular lens or other complications. Furthermore, all patients informed to immediately report any deterioration, severe pain or sudden drop in vision.

Data collection was conducted using a pre-constructed data collection form (case-sheet) prepared for the purposes of this study including two parts; the demographic characteristics of the patients (age, gender, weight, height, body mass index, residence, occupation, medical history of chronic diseases, history of medication use, steroids or cholesterol lowering medications, surgical history, family history, smoking history and alcohol consumption. The second part was the clinical information including the preoperative clinical examination, results of investigations, ultrasonography findings, operative findings and information and postoperative follow up assessment. Data of all patients were entered and analyzed using the statistical package for social sciences, version 22 . Appropriate statistical tests and procedures were applied accordingly. Level of significance was set at or below 0.05 as a significant difference or association. All statistical analyses performed with the aid of community medicine specialist physician certified for statistical analysis.

\section{Results and Discussion}

In this prospective study a total of 168 patients were prospectively assessed preoperatively, enrolled, the mean age of the studied group was $58.2 \pm 14.7$ (range: $38-$ $81)$ years, on the other hand, 27 patients $(16.1 \%)$ aged less than 50 years and $141(83.9 \%)$ aged 50 years or more. Females were relatively dominant than 93/168 (55.4\%) and males were $75(44.6 \%)$. Out of the 168 patients, employed were $47(28 \%)$ and unemployed were $121(72 \%)$. Majority of the patients, (78.6\%), were urban residents. The mean body mass index (BMI) was $26.4 \pm$ 
$6.3 \mathrm{~kg} / \mathrm{m}^{2}$, moreover, 65 patients $(38.7 \%)$ were obese $\left(\mathrm{BMI} \geq 30 \mathrm{~kg} / \mathrm{m}^{2}\right)$ and the remaining $103(61.3 \%)$ were non-obese (BMI below $30 \mathrm{~kg} / \mathrm{m}^{2}$ ). Regarding the medical history, $38(22.6 \%)$ patients were hypertensive, 24 (14.3\%) diabetic, $11(6.5 \%)$ patients had other chronic diseases including cardiovascular, renal impairment and asthma. Twenty seven patients had history of surgeries, and $35(20.8 \%)$ had positive family history. Additionally, $53(31.5 \%)$ patients were smoker and only 3 patients $(1.8 \%)$ were alcohol consumer, (Table 1).

The ultrasound examination revealed that 21 patients (12.5\%) had abnormal posterior segment findings while the remaining 147 (87.5\%) patients were normal (Figure 1). Among the detected 21 abnormal ultrasound findings retinal detachment were the more frequent 11/21 (52.4\%) and represented $6.5 \%$ out of the total 168 patients, vitreous haemorrhage found in 7/21patients (33.3\%), posterior vitreous detachment in 3 patients (14.3\%), asteroid hyalosis in 3 patients (14.3\%), Two patients (9.5\%) had intra-ocular foreign body and two patients had posterior staphyloma, it is worth mentioned, that four patients had more than one lesion at the same time, (Table 2).

To assess the possible correlation between abnormal ultrasound findings and risk factors among the patients, cross-tabulation was performed for the ultrasound findings (normal or abnormal) against the patients baseline characteristics, this analysis revealed that younger age, below 50 years, cataract patients were about 3-fold more likely to have abnormal ultrasound findings than the older patients of 50 years or above, by $(\mathrm{OR}=3.0, \mathrm{P}=0.026)$.

Other significant association was found between the diabetes mellitus and abnormal ultrasound findings, where diabetic patients had significantly more frequent abnormal ultrasound findings than non-diabetic by almost 4 times $(\mathrm{OR}=3.82, \mathrm{P}=0.019)$. No statistically significant association had been found with other variables, $(\mathrm{P}>0.05)$. Fortunately, none of the patients had serious complication or impaired vision after surgery, the only observed postoperative complaints of the patients were mild pain and discomfort reported by two patients, and visual acuity was $6 / 18$ in one patients while all other patients had $6 / 12$ or better visual acuity.

Cataract is one of the commonest ocular diseases seen by ophthlmologists on almost daily practice. Cataracts constitute an important cause of blindness in developing countries and many patients have advanced cataracts that interfere with the visualization of fundus before cataract surgery (Salman, Parmar, Vanila, Thomas, \& Jesudasan, 2006). Visualization of fundus is considered very important in many circumstances to get accurate prognostic evaluation of the vision postoperatively. Hence, ultrasonographic examination prior to cataract surgeries can be very useful to get significant information about the ocular abnormalities and changes found among patients intended to have cataract surgeries. Many studies worldwide documented that such alterations may interfere with the visual prognosis or even contraindicate cataract surgery (Bello \& Adeoti, 2006; Scott, Smiddy, Feuer, \& Ehlies, 2004; Thanigasalam et al., 2015). Ultrasonographic changes in the posterior segment were described in the literature to contribute $13 \%-20 \%$ of patients with cataract (Anteb, Blumenthal, Zamir, \& Waindim, 1998; Qureshi \& Laghari, 2010). Hence the present study tried to assess the role of ultrasound examination before cataract surgery and to assess the ultrasound abnormal findings reported among patients who are planned to get cataract surgery, therefore a total of 168 cataract patients were enrolled in this study and they were prepared to underwent cataract surgery. The selected patients have unilateral cataract and this selection made on the base that we can compare the findings of the patients with the contralateral eye. In the present study, $12.5 \%$ of the patients had ultrasound abnormalities, demonstrating the importance of performing this test as a preoperative evaluation in patients with cataract, however, frequency of abnormalities reported in our study was higher than that reported by Bello and Adeoti in 2006, who found only $5.2 \%$ of the patients had abnormal ultrasound findings (Bello and Adeoti, 2006). On the other hand, higher rate of abnormal ultrasound findings were reported in India by Salman et al., (2006) where 29.8\% of 394 Indian cataract patients had abnormal ultrasound findings. Moreover, Qureshi and Laghari found that 90 out of 750 cataract patients had posterior segment lesions on ultrasound examination before cataract surgery which is very close to our findings. However, the abnormal ultrasound findings varied across different studies and countries and this might be attributed to the differences in the facilities and availability of modern ultrasound systems (Salman et al., 2006). In details, the current study found that Retinal detachment (RD) was the most frequent diagnosed lesion among the studied group it was reported in 11/21 cases and represented (6.5\%) of all cases, this finding was lower than that reported in previous study was conducted by Corrêa et al., (Corrêa $e t$ al., 2002) who found retinal detachment in $9.7 \%$ of cases, 
Table.1 Baseline preoperative characteristics of 168 cataract patients

\begin{tabular}{llcc}
\hline \multirow{2}{*}{ Variable } & \multicolumn{2}{c}{ Value } & $\%$ \\
\hline Age (year) & $<50$ & 27 & $16.1 \%$ \\
\cline { 2 - 4 } & $\geq 50$ & 141 & $83.9 \%$ \\
\cline { 2 - 4 } (mean \pm SD*) & $58.2 \pm 14.7$ & - \\
\hline Occupation & Male & 75 & 44.6 \\
\cline { 2 - 4 } & Female & 93 & 55.4 \\
\hline Residence & Employed & 47 & 28.0 \\
\cline { 2 - 4 } & Unemployed & 121 & 72.0 \\
\hline Obesity & Urban & 132 & 21.4 \\
\cline { 2 - 4 } & Rural & 36 & 38.7 \\
\hline Hypertension & Obese & 65 & 61.3 \\
\cline { 2 - 4 } & Non-obese & 103 & 22.6 \\
\hline Diabetes mellitus & & 38 & 14.8 \\
\hline Other chronic diseases & 24 & 6.5 \\
\hline Surgical history & & 11 & 16.1 \\
\hline Family history & & 27 & 31.5 \\
\hline Smoking & & 35 & 14.8 \\
\hline
\end{tabular}

SD: standard deviation

Table.2 Preoperative Ultrasound findings of 168 cataract patients

\begin{tabular}{lccc}
\hline & No. of & \multicolumn{2}{c}{ Percent } \\
\cline { 3 - 4 } Posterior Segment Lesion & patients & $\begin{array}{c}\text { Out of 21 } \\
\text { abnormal }\end{array}$ & $\begin{array}{c}\text { Out of 147 } \\
\text { normal }\end{array}$ \\
\hline Retinal detachment & 11 & 52.4 & 6.5 \\
Vitreous hemorrhage & 7 & 33.3 & 4.2 \\
Posterior vitreous detachment & 3 & 14.3 & 1.8 \\
Asteroid hyalosis & 3 & 14.3 & 1.8 \\
Intra-ocular foreign body & 2 & 9.5 & 1.2 \\
Posterior staphyloma & 2 & 9.5 & 1.2 \\
\hline
\end{tabular}


Table.3 Cross-tabulation for the ultrasound finding against patients characteristics

Ultrasound findings

\begin{tabular}{|c|c|c|c|}
\hline $\begin{array}{l}\text { Abnormal } \\
(\mathrm{n}=21)\end{array}$ & $\begin{array}{l}\text { Normal } \\
(\mathrm{n}=147)\end{array}$ & Total & OR \\
\hline
\end{tabular}

Variable

No. Row $\%$ No. Row $\%$

\begin{tabular}{|c|c|c|c|c|c|c|c|c|}
\hline \multirow[t]{2}{*}{ Age (year) } & $<50$ & 7 & 25.9 & 20 & 74.1 & 27 & \multirow{2}{*}{$\begin{array}{c}3.00 \\
(1.08-8.30)\end{array}$} & \multirow{2}{*}{0.026} \\
\hline & $>50$ & 14 & 9.9 & 127 & 90.1 & 141 & & \\
\hline \multirow[t]{2}{*}{ Gender } & Male & 8 & 10.7 & 67 & 89.3 & 75 & \multirow{2}{*}{$\begin{array}{c}0.73 \\
(0.29-1.88)\end{array}$} & \multirow{2}{*}{0.68} \\
\hline & Female & 13 & 14.0 & 80 & 86.0 & 93 & & \\
\hline \multirow[t]{2}{*}{ Hypertension } & Yes & 6 & 15.8 & 32 & 84.2 & 38 & \multirow{2}{*}{$\begin{array}{c}1.44 \\
(0.52-4.0)\end{array}$} & \multirow{2}{*}{0.67} \\
\hline & No & 15 & 11.5 & 115 & 88.5 & 130 & & \\
\hline \multirow[t]{2}{*}{ Diabetes } & Yes & 7 & 29.2 & 17 & 70.8 & 24 & \multirow{2}{*}{$\begin{array}{c}3.82 \\
(1.35-10.80)\end{array}$} & \multirow{2}{*}{0.019} \\
\hline & No & 14 & 9.7 & 130 & 90.3 & 144 & & \\
\hline Other chronic & Yes & 2 & 18.2 & 9 & 81.8 & 11 & 1.61 & \\
\hline diseases & No & 19 & 12.1 & 138 & 87.9 & 157 & $(0.32-8.04)$ & 0.91 \\
\hline \multirow{2}{*}{ Surgical history } & Yes & 2 & 7.4 & 25 & 92.6 & 27 & \multirow{2}{*}{$\begin{array}{c}0.51 \\
(0.11-2.35)\end{array}$} & \multirow{2}{*}{0.57} \\
\hline & No & 19 & 13.5 & 122 & 86.5 & 141 & & \\
\hline \multirow{2}{*}{ Family history } & Positive & 3 & 8.6 & 32 & 91.4 & 35 & \multirow{2}{*}{$\begin{array}{c}0.60 \\
(0.17-2.16)\end{array}$} & \multirow{2}{*}{0.62} \\
\hline & Negative & 18 & 13.5 & 115 & 86.5 & 133 & & \\
\hline \multirow[t]{2}{*}{ Obesity } & Obese & 9 & $13.8 \%$ & 56 & $86.2 \%$ & 65 & \multirow{2}{*}{$\begin{array}{c}1.22 \\
(0.48-3.08)\end{array}$} & \multirow{2}{*}{0.86} \\
\hline & Non-obese & 12 & $11.7 \%$ & 91 & $88.3 \%$ & 103 & & \\
\hline \multirow[t]{2}{*}{ Smoking } & Smoker & 6 & 11.3 & 47 & 88.7 & 53 & \multirow{2}{*}{$\begin{array}{c}0.85 \\
(0.31-2.33)\end{array}$} & \multirow{2}{*}{0.95} \\
\hline & Non-smoker & 15 & 13.0 & 100 & 87.0 & 115 & & \\
\hline Alcohol & Yes & 1 & 14.3 & 6 & 85.7 & 7 & 3.63 & \multirow[b]{2}{*}{0.82} \\
\hline consumption & No & 20 & 12.4 & 141 & 87.6 & 161 & $(0.31-41.8)$ & \\
\hline
\end{tabular}

OR: odds ratio, $\mathrm{CI}$; confidence interval 
Fig.1 Changes of eye lens in cataract, (A) Transparent healthy, (B) opacified cataract lens, adopted from http://mdsaude.com/

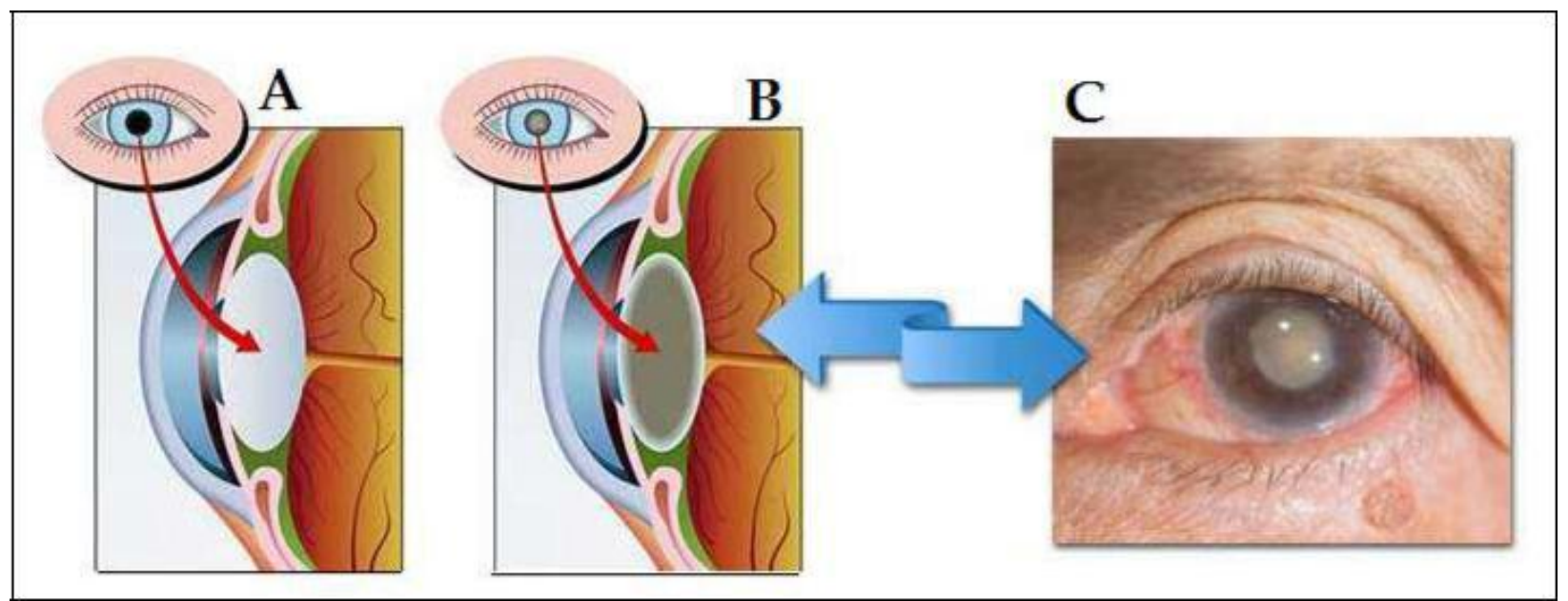

Fig.2 Distribution the 168 cataract patients according to the ultrasound findings

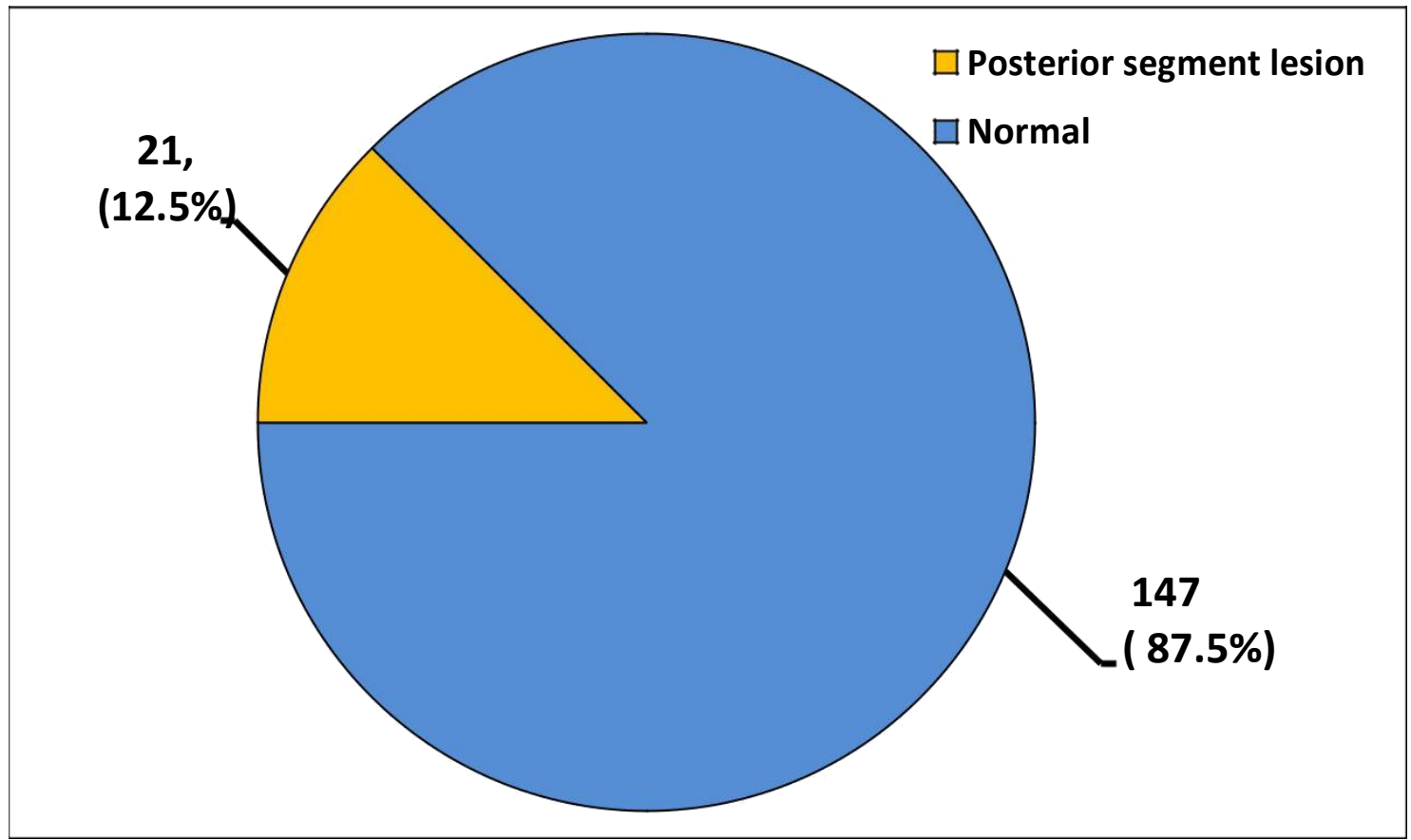

However, other previous studies found retinal detachment was the more frequent finding and its incidence ranged between $1.7 \%$ to $4.1 \%$ (Bello \& Adeoti, 2006; Corrêa et al., 2002; Moorfields Eye Hospital, 2015; Qureshi \& Laghari, 2010; Salman et al., 2006) which agreed our study in that retinal detachment $(\mathrm{RD})$ is the more frequent detected lesion. The diagnosis of RD through ocular ultrasonography allows the evaluation of its characteristics, and the appropriate conduct for each case. Vitreous hemorrhages were also observed in 7 patients $(4.2 \%)$, and in most cases their encounter was not a factor of surgical contraindication. Other findings including posterior vitreous detachment, asteroid hyalosis, intra-ocular foreign body and posterior staphyloma were less frequent and contributed for 1.2 to $1.8 \%$ among the studied group. The present study found a significant relationship between younger age and abnormal ultrasound findings where patients younger than 50 years of age had higher frequency of abnormal findings compared to those of 50 years old or above, other significant relationship was reported with diabetes mellitus, where diabetic patients more likely to have 
abnormal findings on ultrasound examination. These findings were consistent with that reported in previous studies; Salman et al., found that, diabetes mellitus and age below 50 years were significantly associated with a high incidence of abnormal ultrasound findings and the odds ratio was 4.9 and 15.4, respectively(Salman et al., 2006) these findings also supported by previous study in 2015 conducted by Thanigasalam et al., who reported that diabetes mellitus responsible for many ocular alterations including proliferative diabetic and nonproliferative diabetic retinopathy, diabetic maculopathy, vitreous hemorrhage and others (Thanigasalam et al., 2015).

Through the results of the present study and the ultrasound abnormal findings detected in cataract patients before surgery indicated and confirmed that ocular ultrasonography is important before cataract surgery and can play a significant role as a diagnostic tool for diagnosis and detection of hidden lesions and it can be preoperative performed as one of the routine investigations for cataract patients, to help in planning for surgeries and to get more precise prognostic information.

\section{Ethical issues}

All official agreements were obtained prior to initiate the study. All patients were informed about the nature and aims of the study and verbal and written signed consent were obtained from all patients. Data of the participants were kept confidentially and any identification information were hided like names and phone numbers and patients data were collected according to the declaration of Helsinki 2000.

\section{References}

Abraham AG, Condon NG, W. G. E. (2006). The new epidemiology of cataract. Ophthalmol Clin North Am, 19(4), 415-425.

Andley, U. P. (2007). Crystallins in the eye: function and pathology. Progress in Retinal and Eye Research, 26(1), 78-98.

Anteb, M., Blumenthal, E., Zamir, E., \& Waindim, P. (1998). The role of preoperative ultrasonography for patients with dense cataract: a retrospective study of 509 cases. Ophthalmic Surg Lasers, 29, 114-118.

Bello, T. O., \& Adeoti, C. O. (2006). Ultrasonic assessment in pre-operative cataract patients. The Nigerian Postgraduate Medical Journal, 13(4), 326-328.

Candia, O. A. (2004). Electrolyte and fluid transport across corneal, conjunctival and lens epithelia. Experimental Eye Research, 78(3), 527-535.

Chavda, D., Shah, N., \& Sharma, R. (2017). A Study of Role of B Scan Ultrasound in Posterior Segment Pathology of Eye, 6(4), 2015-2017.

Corrêa, Z., Goldhardt, R., Marcon, A., \& Marcon, I. (2002). Ultrasound findings in patients with total cataract. Arq Bras Oftalmol, 65, 609-613.

Duker, Myron Yanoff, J. S. (2008). Eye lens, Function and Anatomy. In M. Y. Duker (Ed.), Ophthalmology (3rd ed., pp. 382-386). Edinburgh: Mosby.

Grimfors, M., Lundstrom, M., Hoijer, J., \& Kugelberg, M. (2017). Intraoperative difficulties, complications and selfassessed visual function in cataract surgery. Acta Ophthalmologica, 1-8.

Joshi, R. (2013). Primary posterior capsular opacification in Indian rural population undergoing cataract surgery for hypermature senile cataract. Clinical Ophthalmology, 8(4), $122-128$

Linebarger EJ, Hardten DR, Shah GK, Lindstrom RL (1999). Phacoemulsification and modern cataract surgery Surv Ophthalmol, 44(2), 1-2.

Moorfields Eye Hospital. (2015). Laser assisted versus standard ultrasound cataract surgery. Fact Patient Information Sheet, (March 2015), 1-8.

Qureshi, M. A., \& Laghari, K. (2010). Role of B-scan ultrasonography in pre-operative cataract patients. International Journal of Health Sciences, 4(1), 31-37.

Salman, A., Parmar, P., Vanila, C. G., Thomas, P. A., \& Jesudasan, N. C. A. (2006). Is ultrasonography essential before surgery in eyes with advanced cataracts? Journal of Postgraduate Medicine, 52(1), 19-22.

Scott, I., Smiddy, W., Feuer, W., \& Ehlies, F. (2004). The impact of echography on evaluation and management of posterior segment disorders. Am J Ophthalmol, 137, 24- 9.

Thanigasalam, T., Reddy, S., \& Zaki, R. (2015). Factors associated with complications and postoperative visual outcomes of cataract surgery; A study of 1,632 cases. Journal of Ophthalmic and Vision Research, 10(4), 375384.

Zafar, D., Mirza, S. A., \& Adul Qadeer, B. (2008). Role of BScan Ultrasonography for Posterior Segment Lesions. J Liaquat Uni Med Health Sci, 7(1), 7-12.

\section{How to cite this article:}

Nadya Abid Hadi. 2018. Role of Ultrasound in Cataract Surgery -A Prospective Clinical Study. Int.J.Curr.Res.Aca.Rev. 6(6), 80-87. doi: https://doi.org/10.20546/ijcrar.2018.606.011 